\title{
Cytokine profiling of pulmonary aspergillosis
}

\section{H. Sambatakou, ${ }^{*} † \S$ V. Pravica,‡ I. V. Hutchinson‡ \& D. W. Denning*}

\section{Summary}

Aspergillus fumigatus is ubiquitous and yet causes invasive, chronic and allergic disease of the lung. Chronic cavitary pulmonary aspergillosis (CCPA) is a slowly destructive form of pulmonary aspergillosis, without immunocompromise. We hypothesized that CCPA cytokine gene polymorphisms would differ from patients with allergic bronchopulmonary aspergillosis (ABPA) and uninfected controls.

We have profiled functional cytokine gene polymorphisms for interleukin (IL)-10, IL-15, transforming growth factors (TGF)- $\beta 1$, tumour necrosis factor (TNF)- $\alpha$ and interferon (IFN)- $\gamma$ in patients with CCPA $(n=24)$ who were compared with other forms of aspergillosis (mostly ABPA) $(n=15)$ and with ethnically matched controls $(n=$ 65-330). Results are described with reference to the highproducing genotype in each case.

Susceptibility to aspergillosis (all patients compared with normal controls) was associated with higher frequency of the IL-15 $+13689 * \mathrm{~A}$ allele $(\mathrm{OR}=2.37, P=0.0028)$ and A/A genotype $\left(\chi^{2}=10.31, P<0.001\right)$, with a lower frequency of the TNF- $\alpha-308 *$ A/A genotype $\left(\chi^{2}=11.05\right.$, $P<0.01)$. Within the aspergillosis patients, CCPA is associated with lower frequency of the IL-10 $-1082 * \mathrm{G}$ allele $(\mathrm{OR}=0.38, P=0.0006)$ and $\mathrm{G} / \mathrm{G}$ genotype $\left(\chi^{2}=\right.$ $22.45, P<0.001)$ and with a lower frequency of the TGF- $\beta 1+869 *$ T allele $(\mathrm{OR}+0.42, P<0.0029)$ and T/T genotype $\left(\chi^{2}=17.82, P<0.001\right)$ compared with nonCCPA patients and normal controls.

Patients infected with Aspergillus appear to be higher producers of IL-15, a Th2-promoting cytokine, and lower producers of TNF- $\alpha$, a cytokine central in protective responses. CCPA occurs in patients who are genetically lower producers of both IL-10 and TGF- $\beta 1$. As these cytokines are regulatory and anti-inflammatory, CCPA may be a consequence of poor inflammatory response control in the lung.

\footnotetext{
* The School of Medicine, The University of Manchester, Oxford Road, Manchester, UK, + Wythenshawe Hospital, Southmoor Road, Manchester M23 9LT, UK, ₹ The Faculty of Life Sciences, Michael Smith Building, The University of Manchester, Oxford Road, Manchester, UK. $\mathbb{S}$ Present address: Department of Medicine, University of Athens, Athens, Greece.

Received 7 March 2006; revised 26 April 2006; accepted 8 June 2006

Correspondence: David W. Denning, Education and Research Centre, Wythenshawe Hospital, Southmoor Rd, Manchester M23 9LT, UK. Tel: +44 (0)161291 5811; Fax: +44 (0) 161291 5806;

E-mail: ddenning@manchester.ac.uk
}

\section{Introduction}

Aspergillus fumigatus is unique among microorganisms in causing severe invasive infection in those with immunocompromised states, allergy in atopic patients and indolent progressive infection in those without immunodeficiency but prior pulmonary insults. This spectrum of disease offers a special opportunity to understand the relationship of the host and pathogen. Chronic pulmonary aspergillosis comprises chronic cavitary (CCPA) and chronic fibrosing pulmonary aspergillosis (CFPA) as well as simple aspergilloma (Denning et al., 2003). The background cause of CCPA and CFPA has been little investigated. We have previously documented defects in innate immunity (mannosebinding protein and more recently surfactant) in these patients (Crosdale et al., 2001; Vaid et al., unpublished data). Allergic bronchopulmonary aspergillosis, allergic fungal sinusitis and the recently coined term severe asthma with fungal sensitisation (SAFS) (Denning et al., 2006) comprise the main allergic diseases associated with exposure to A. fumigatus. We care for many of these patients in our clinic and so we took the opportunity to compare their genetic backgrounds with respect to candidate pro- and anti-inflammatory cytokines that might influence the development and outcome of CCPA.

Macrophages have been shown to participate in the early phase of defence against Aspergillus conidia (Waldorf et al., 1984; de Repentigny et al., 1993; Rhodes, 1993; Cenci et al., 1998; Duong et al., 1998), whereas neutrophils and circulating monocytes cause damage to escaping hyphae (late phase of defence) by secreting microbicidal oxidative metabolites and non-oxidative compounds (Schaffner et al., 1982; Levitz et al., 1986; Roilides et al., 1996). However, the role of cytokines in the modulation of responses of circulating or tissue phagocytes to Aspergillus has only recently begun to be elucidated. There are experimental data suggesting the protective role of Th1 CD4+ predominance against invasive aspergillosis in the imbalance of Th1/Th2 response (Cenci et al., 1997, 1998, 2000). In experimental invasive aspergillosis, certain inbred mouse stains are substantially more susceptible (notably DBA $\left./ 2\left(\mathrm{H}^{\mathrm{d}}\right)\right)$ compared with others, such as BALB/c $\left(\mathrm{H}-2^{\mathrm{d}}\right)$ and $\left(57 \mathrm{BL} / 6\left(\mathrm{H}-2^{\mathrm{d}}\right)\right.$. The difference in susceptibility appears to be determined primarily by the balance between CD4+, Th1 and Th2 responses (Cenci et al., 1997, 1998). Th1 cell responses are associated with resistance and onset of protective immunity, whereas Th2 responses are associated with progressive disease, more tissue damage 
and poor survival. Th1-produced cytokines [including interferon (IFN)- $\gamma$, interleukin (IL)-6, IL-12, tumour necrosis factor (TNF)- $\alpha$, IL-1] activate neutrophils and pulmonary macrophages, the key effector cells in invasive aspergillosis, whereas Th2 cytokines, notably IL-4 and IL-10, are associated with reduced IL-12 and TNF- $\alpha$ and worse outcome. IL-10-knock-out mice survive an otherwise lethal challenge (Clemons et al., 2000) and IL4-knock-out mice show deficient Th2 responses and are more resistant to infection (Cenci et al., 1999). Additional work supports this hypothesis as antagonism of TNF$\alpha$ resulted in increased death in experimentally infected mice and more fungal burden in the lungs, whereas a TNF- $\alpha$ agonist peptide improved survival (Mehrad et al., 1999). Chemokines appear to enhance the recruitment and effector functions of lymphocytes and macrophages and contribute to granuloma formation and fibrosis. It is hypothesized that a Th1/Th2 dysregulation and a switch to a Th2 immune response may contribute to development and unfavourable outcome of invasive asperillosis in humans. Investigating this in patients with acute invasive aspergillosis is challenging, because there are multiple other confounding factors (such as temporary neutropenia and variable corticosteroid doses).

\section{Patients, material and methods}

We have investigated the functional polymorphisms in certain cytokines in patients with CCPA $(n=24)$ and those were compared with other forms of aspergillosis [mostly allergic bronchopulmonary aspergillosis (ABPA) $(n=9)$, SAFS $(n=2)(1)$, allergic fungal sinusitis $(n=1)$ and others $(n=3)]$ and with normal ethnically matched controls $(n=65-330)$. The duration of the disease in patients with CCPA ranged from several months to $>12$ years. The clinical, radiological characteristics and the outcome for a proportion of the patients who were recruited in the present study have been described in a comprehensive recent article (Denning et al., 2003). The control population consisted of British Caucasoid individuals who were typed for the polymorphism using amplification refractory mutation system-polymerase chain reaction (ARMS-PCR) as previously described (Perrey et al., 1998). British Caucasoid controls were unrelated, healthy volunteers with an age range of 20-60 years. They were from the north-west region of England. For IL-10, 330 controls, for IL-15 65, for IFN- $\gamma 164$, for transforming growth factors (TGF)- $\beta 107$ and for TNF- $\alpha$ 106 controls were compared with patients.

After the informed written consent was obtained from the patients to use their DNA for enhancing scientific knowledge of their disease, peripheral blood was drawn and DNA was extracted from EDTA blood samples and typed for polymorphisms in genes encoding IL-10, IL-15, TGF- $\beta 1$, TNF- $\alpha$ and IFN- $\gamma$ using sequence-specific primers (SSP)-PCR methodology. Genomic DNA from whole frozen EDTA-containing samples was obtained by phenol extraction and ethanol precipitation following proteinase K (Boeringer Mannheim, Lewes, UK) digestion. Commer- cially available DNA extraction kits have been used successfully in other studies. Polymorphisms were identified using SSP-PCR methodology, as previously described (Perrey et al., 1998), using allele-specific primers to identify the high and low producer alleles of each biallelic polymorphic site for IL-10 gene $(-1082 * \mathrm{G} / \mathrm{A}$ and $-592 * \mathrm{C} /$ A, respectively), TNF- $\alpha-308 * \mathrm{G} / \mathrm{A}, \mathrm{IL}-15(-80 * \mathrm{~T} / \mathrm{C}$ and $+13689 * \mathrm{~T} / \mathrm{A}), \mathrm{IFN}-\gamma(+874 * \mathrm{~T} / \mathrm{A}), \mathrm{TGF}-\beta 1(+869 * \mathrm{~T} / \mathrm{C}$, codon 10).

The protocol for the PTC-100 PCR machine (MJ Research Inc, Waltham, MAA) was as follows: $95^{\circ} \mathrm{C}$ for $1 \mathrm{~min}$; then 10 cycles at $95^{\circ} \mathrm{C}$ for $15 \mathrm{~s}, 65^{\circ} \mathrm{C}$ for $50 \mathrm{~s}$ and $72{ }^{\circ} \mathrm{C}$ for $40 \mathrm{~s}$; followed by 20 cycles at $95^{\circ} \mathrm{C}$ for $20 \mathrm{~s}$, $59^{\circ} \mathrm{C}$ for $50 \mathrm{~s}$, and $72^{\circ} \mathrm{C}$ for $50 \mathrm{~s}$. DNA products were then analysed using electrophoresis on $2 \%$ agarose gel. IFN- $\gamma$ assay has been described elsewhere (Pravica et al., 2000). Following electrophoresis, gels were stained with ethidium bromide $\left(10 \mathrm{mg} \mathrm{L}^{-1}\right)$, visualized with UV light on a transilluminator and photographed for the definition and identification of alleles.

Odds ratios (OR) with $95 \%$ confidence intervals were calculated to compare allele frequencies and genotype frequencies, after transformation into percentages, using the $\chi^{2}$ test.

\section{Results}

Genotypes of 24 CCPA patients were compared with 15 patients with allergic forms of aspergillosis. The results of the distribution of genotypes and alleles are shown in Tables 1-3.

\section{Susceptibility to aspergillosis}

Aspergillosis is associated with higher frequency of the IL-15 +13689*A allele [OR = $2.37(1.34-4.20), P=$ $0.0028]$ and A/A genotype $\left(\chi^{2}=10.31, P<0.001\right)$ compared with normal controls, but not the IL-15-80 polymorphism. Aspergillosis is also associated with a lower frequency of the TNF- $\alpha-308 * \mathrm{~A} / \mathrm{A}$ genotype $\left(\chi^{2}=11.05\right.$, $P<0.01)$, and a higher frequency of IFN- $\gamma(+874) \mathrm{T} / \mathrm{T}$ genotype $\left(\chi^{2}=8.16, P<0.02\right)$ but no particular allele on its own with either gene. There was no association with IL-10 or TGF- $\beta 1$ genotype or allele.

\section{CCPA vs. allergic aspergillosis}

Among the aspergillosis patients, CCPA is associated with lower frequency of the IL-10 $-1082 * \mathrm{G}$ allele $[\mathrm{OR}=0.38$ (0.21-0.67), $P=0.0006]$ and $\mathrm{G} / \mathrm{G}$ genotype $\left(\chi^{2}=22.45\right.$, $P<0.001)$ compared with those with allergic disease, but not the IL-10 -592 polymorphism. In addition, CCPA was associated with a lower frequency of the TGF- $\beta 1$ $+869 *$ T allele $[\mathrm{OR}+0.42(0.24-0.75), P<0.0029]$ and T/T genotype $\left(\chi^{2}=17.82, P<0.001\right)$ compared with non-CCPA patients and normal controls $[\mathrm{OR}+0.32(0.15-$ 0.64), $P=0.001$ (T allele) and $\chi^{2}=19.26, P>0.001$ ( T/T genotype)]. There was no association with IL-15, IFN- $\gamma$ or TNF- $\alpha$ genotype or allele. 
Table 1. Frequencies (\%) of IL-10 (at position -1082 and -592) alleles and genotypes

\begin{tabular}{|c|c|c|c|c|c|c|c|c|c|c|}
\hline \multirow[b]{2}{*}{ Groups } & \multicolumn{2}{|c|}{$\begin{array}{c}\mathrm{IL}-10 \\
(-1082) \text { allele }\end{array}$} & \multicolumn{3}{|c|}{ IL-10 (-1082) genotype } & \multicolumn{2}{|c|}{$\begin{array}{c}\mathrm{IL}-10 \\
(-592) \text { allele }\end{array}$} & \multicolumn{3}{|c|}{ IL-10 (-592) genotype } \\
\hline & G & A & $\mathrm{G} / \mathrm{G}^{*}$ & $\mathrm{G} / \mathrm{A}$ & A/A & C & A & $\mathrm{C} / \mathrm{C}^{*}$ & $\mathrm{C} / \mathrm{A}$ & $\mathrm{A} / \mathrm{A}$ \\
\hline 1. CCPA & 39 & 61 & 17 & 43 & 39 & 75 & 25 & 56 & 38 & 6 \\
\hline 2. Other aspergillosis groups & 63 & 37 & 40 & 47 & 13 & 73 & 27 & 54 & 38 & 8 \\
\hline 3. All aspergillosis combined & 49 & 51 & 26 & 45 & 29 & 74 & 26 & 55 & 38 & 7 \\
\hline 4. Normal controls & 51 & 49 & 30 & 42 & 28 & 77 & 23 & 59 & 34 & 8 \\
\hline Comparisons & \multicolumn{2}{|c|}{$\begin{array}{l}1 \text { vs. } 2 \\
\text { OR }=0.38 \\
(0.21-0.67) \\
P=0.0006\end{array}$} & \multicolumn{3}{|c|}{$\begin{array}{l}1 \text { vs. } 2 \\
\chi^{2}=22.45, P<0.001 \\
3 \text { vs. } 4 \\
\text { no differences }\end{array}$} & ns & ns & & & \\
\hline
\end{tabular}

* High producer genotype.

Table 2. Frequencies (\%) of IL-15 (at positions -80 and +13689 ) alleles and genotypes

\begin{tabular}{|c|c|c|c|c|c|c|c|c|c|c|}
\hline \multirow[b]{2}{*}{ Groups } & \multicolumn{2}{|c|}{$\begin{array}{c}\mathrm{IL}-15 \\
(-80) \text { alleles }\end{array}$} & \multicolumn{3}{|c|}{ IL-15 (-80) genotypes } & \multicolumn{2}{|c|}{$\begin{array}{c}\text { IL-15 } \\
(+13689) \\
\text { alleles }\end{array}$} & \multicolumn{3}{|c|}{ IL-15 (+13689) genotypes } \\
\hline & $\mathrm{T}$ & $\mathrm{C}$ & $T / T^{*}$ & $\mathrm{C} / \mathrm{T}$ & $\mathrm{C} / \mathrm{C}$ & A & $\mathrm{T}$ & $\mathrm{A} / \mathrm{A}^{*}$ & $\mathrm{~T} / \mathrm{A}$ & $T / T$ \\
\hline 1. CCPA & 21 & 79 & 0 & 42 & 58 & 63 & 37 & 39 & 48 & 13 \\
\hline 2. Other aspergillosis groups & 30 & 70 & 0 & 60 & 40 & 70 & 30 & 47 & 47 & 7 \\
\hline 3. All aspergillosis combined & 24 & 76 & 0 & 49 & 51 & 66 & 34 & 42 & 47 & 11 \\
\hline 4. Normal controls & 31 & 69 & 5 & 34 & 61 & 45 & 55 & 28 & 44 & 28 \\
\hline Comparisons & ns & ns & & & & & & 3 vs. 4 & 10.31 & .01 \\
\hline
\end{tabular}

* High producer genotype.

Table 3. Frequencies (\%) of TNF- $\alpha(-308)$, IFN-gamma (+874), TGF- $\beta$ (+869) alleles and genotypes

\begin{tabular}{|c|c|c|c|c|c|c|c|c|c|c|c|c|c|c|c|}
\hline \multirow[b]{2}{*}{ Groups } & \multicolumn{2}{|c|}{$\begin{array}{l}\text { TNF- } \alpha \\
-308 \\
\text { alleles }\end{array}$} & \multicolumn{3}{|c|}{$\begin{array}{c}\text { TNF- } \alpha-308 \\
\text { genotypes }\end{array}$} & \multicolumn{2}{|c|}{$\begin{array}{l}\text { IFN- } \gamma \\
(+874) \\
\text { alleles }\end{array}$} & \multicolumn{3}{|c|}{$\begin{array}{c}\text { IFN- } \gamma(+874) \\
\text { genotypes }\end{array}$} & \multicolumn{2}{|c|}{$\begin{array}{l}\text { TGF- } \beta \\
(+869) \\
\text { alleles }\end{array}$} & \multicolumn{3}{|c|}{ TGF- $\beta(+869)$} \\
\hline & A & G & $A / A^{*}$ & G/A & $\mathrm{G} / \mathrm{G}$ & $\mathrm{T}$ & A & $T / T^{*}$ & $\mathrm{~T} / \mathrm{A}$ & $\mathrm{A} / \mathrm{A}$ & T & C & $\mathrm{T} / \mathrm{T}^{*}$ & $\mathrm{C} / \mathrm{T}$ & $\mathrm{C} / \mathrm{C}$ \\
\hline 1. CCPA & 26 & 74 & 4 & 43 & 52 & 59 & 41 & 39 & 39 & 22 & 43 & 57 & 18 & 50 & 32 \\
\hline 2. Other aspergillosis groups & 10 & 90 & 0 & 20 & 80 & 60 & 40 & 40 & 40 & 20 & 64 & 36 & 43 & 43 & 14 \\
\hline 3. All aspergillosis combined & 20 & 80 & 3 & 34 & 63 & 59 & 41 & 39 & 39 & 21 & 51 & 49 & 28 & 47 & 25 \\
\hline 4. Normal controls & 27 & 73 & 16 & 23 & 61 & 48 & 52 & 21 & 54 & 25 & 65 & 35 & 41 & 48 & 11 \\
\hline Comparisons & ns & & \multicolumn{3}{|c|}{$\begin{array}{l}\text { 3vs. } 4 \\
\chi^{2}=11.05, P<0.01\end{array}$} & \multicolumn{2}{|l|}{ ns } & \multicolumn{3}{|c|}{$\begin{array}{l}3 \text { vs. } 4 \\
\chi^{2}=8.16, P<0.02\end{array}$} & \multicolumn{2}{|c|}{$\begin{array}{l}1 \text { vs. } 2 ; \\
\text { OR }=0.42 \\
(0.24-0.75) \\
P=0.0029 \\
1 \text { vs. } 4 ; \\
\text { OR }=0.32 \\
(0.15-0.64) \\
P=0.001 \\
3 \text { vs. } 4 ; \\
\text { OR }=0.51 \\
(0.29-0.89) \\
P<0.016\end{array}$} & \multicolumn{3}{|c|}{$\begin{array}{l}1 \text { vs. } 2 ; \chi^{2}=17.82 \\
P<0.001 \\
1 \text { vs. } 4 ; \chi^{2}=19.26 \\
P<0.01 \\
2 \text { vs. } 4 \text { not significant }\end{array}$} \\
\hline
\end{tabular}

\footnotetext{
* High producer genotype.
} 


\section{Discussion}

Despite sequencing the genome (Nierman et al., 2005), the intrinsic reason for the remarkable pathogenicity and allergenicity of $A$. fumigatus compared with any other member of the Aspergillus genus is not yet well understood. Gene polymorphisms of specific host immune defence appear to be of major importance in the risk and manifestation of infectious disease. Allelic variants of cytokine genes are associated with higher or lower production of cytokines both in vitro and in vivo. All steps of host response to infection may be affected by genetic factors. Some examples of genetic defects associated with high rates and predilection for infections that include $\mathrm{Fc}_{\mathrm{c}} \gamma$ receptor, Toll-like receptor or mannose-binding protein mutations have been shown to modify outcome of severe pneumococcal infections, Gram-negative septic shock, and meningococcal disease, respectively. Moreover, TNF polymorphisms have been associated with susceptibility to malaria and other infections; chemokine receptor polymorphisms with susceptibility to HIV; natural resistanceassociated macrophage protein 1 with tuberculosis; and surfactant proteins with respiratory syncytial virus in infants (Kwiatkowski, 2000; McNicholl et al., 2000; Charpentier \& Mira, 2001; Jack et al., 2001; Lofgren et al., 2002). Susceptibility to both chronic pulmonary aspergillosis and ABPA is linked with mannose-binding protein and surfactant A2 defects in some patients (Crosdale et al., 2001; Madan et al., 2005; Vaid et al., unpublished data), and ABPA also with an increased IL10-producing genotype (Brouard et al., 2005), but these clearly do not explain the disease phenotypes alone.

Both innate and adaptive [T helper (Th)] immunity play a central role in fungal infection. A bi-directional function exists between the two arms of the immune response, mainly through cytokine production. Some cytokines may have beneficial or deleterious effects on infection, depending on the dose and timing of endogenous production or exogenous administration (Mencacci et al., 2000).

This pilot study investigated candidate cytokine genes that could contribute to the risk of developing CCPA. Specifically, the study examined genes involved in Th1 and Th2 pathways of the immune response that are critical for effective antifungal activity. The dominance of either Th1 or Th2 pathways directly correlates with the outcome and severity of infection. However, studying of a single cytokine gene, for the mapping of complex diseases, in several published genetic case-control association studies, is not a realistic and informative approach, as the cytokine network is highly flexible and complex, containing interactive cascades of gene activation and suppression, and a considerable overlap between the function of individual cytokines exists. This fact complicates efforts to analyse both the function of individual cytokines and the impact of cytokine gene polymorphism on gene expression and disease, studying each cytokine in isolation.

A novel finding of the present study is that cytokines' genes polymorphisms are associated with the development of CCPA and could explain the devastating consequences of the disease in otherwise healthy individuals without any obvious immune defect.

The IL-15 +13689 A allele and A/A genotype were significantly more common than in controls. The A allele appears to be associated with higher IL-15 production by LPS-stimulated peripheral blood mononuclear cells, while the $\mathrm{T}$ allele appears to be associated with lower IL-15 production, but this remains to be confirmed. IL-15 is supposed to play a role in the activation of Th2 responses. In a previous study, the $+13689 *$ A allele was more frequent in atopic individuals compared with the same control group as that used in this study (I Pravica and IV Hutchinson, unpublished data). The odds ratio was 0.6 $(0.3-0.9), P=0.02$, similar to this study. There were no significant associations of aspergillosis with IL-15 -80 alleles or genotypes. One possible interpretation is that high IL-15 producers are predisposed to aspergillosis because patients make a Th2 response which is not protective. However, in an ex vivo study, IL-15 augmented neutrophil damage of A. fumigatus hyphae (Winn et al., 2003), illustrating the complexity of cytokine action.

With respect to TNF- $\alpha$, the high producer $-308 \mathrm{~A} / \mathrm{A}$ genotype is less frequent in patients with any form of aspergillosis compared with healthy controls. TNF- $\alpha$ is a pro-inflammatory cytokine, important to the host response to infectious challenge, including fungal pathogens. TNF$\alpha$ is secreted very early during infection. In vitro studies have demonstrated that TNF- $\alpha$ enhances specific phagocytic activity against conidia by pulmonary alveolar macrophages (as an early event) and augments the neutrophil damage of Aspergillus hyphae (as a late event) (Roilides et al., 1998). The protective role of TNF- $\alpha$ has also been documented in murine models with invasive aspergillosis (IA): exogenous administration of TNF- $\alpha$ protected animals from IA and lowered mortality as well as the number of organs infected by Aspergillus (Nagai et al., 1995). The development of IA in individuals with autoimmune diseases as an adverse event soon after therapy with anti-TNF- $\alpha$ immunomodulatory treatment has also been reported (De Rosa et al., 2003).

Inheritance of the IL-10 $-1082 \%$ A allele is associated with the development of CCPA in the present study. The A allele is associated with lower IL-10 production by lymphocytes. Because IL-10 is anti-inflammatory, such patients may be more prone to necrotic sequelae. In contrast, non-CCPA aspergillosis is associated with the $\mathrm{G}$ allele (high producer), in accordance with the published data. However, the numbers are too small to see a difference in either group compared with normal controls. A doubling of the numbers in the CCPA group would achieve significance. Interestingly, there were no significant associations of aspergillosis with -592 (monocyte production) alleles or genotypes.

Interleukin-10 exerts inhibitory effects on immune responses, including the functional suppression of phagocytic cells against $A$. fumigatus. IL-10 is constitutively produced by bronchial epithelial cells and potentially inhibits cytokine production by cultured alveolar macrophages and lung dendritic cells. Therefore, the potential role of IL-10 in regulating pulmonary immune responses 
and in suppressing acute inflammation seems to be crucial. Data from studies using murine models have indicated that IL-10 is an important regulator of the T-cell-mediated immune response to A. fumigatus (Kurup \& Grunig 2002; Grunig et al., 1997). Studies in murine models of mice deficient in IL-10 revealed increased resistance to $A$. fumigatus infection, whereas mice expressing high serum IL-10 levels show decreased resistance to aspergillosis and were protected by neutralization of this cytokine (Cenci et al., 1998; Clemons et al., 2000; Centeno-Lima et al., 2002).

In accordance with experimental studies, high IL-10 concentrations in clinical studies have been reported to be associated with severe outcomes in bacterial infections and development of invasive aspergillosis and a possible correlation with unfavourable outcome in non-neutropenic immunocompromised patients (Roilides et al., 2001). In a recent article (Brouard et al., 2005), a significant relationship was found between the $-1082 * \mathrm{G} / \mathrm{G}$ genotype (high producers) and both colonization with $A$. fumigatus and allergic bronchopulmonary aspergillosis (ABPA) in patients with cystic fibrosis. Moreover, measurements of serum IL-10 levels in the same study revealed higher serum IL-10 in patients with $A$. fumigatus-related pulmonary disease.

We found that CCPA occurs in patients who are genetically lower producers of TGF- $\beta 1$, whereas in ABPA, the allele and genotype frequency was consistent with the general population. TGF- $\beta 1$ is produced by several cells and promotes proliferation of fibroblasts and the deposition of collagen. Production of TGF- $\beta 1$ varies between individuals and partly depends on polymorphisms in the TGF- $\beta 1$ gene at positions +869 and +915 encoding codons 10 and 25 . As TGF- $\beta 1$ is an anti-inflammatory cytokine, the development of CCPA may be a consequence of failing to control the inflammatory response. Polymorphisms in TGF- $\beta 1$ are associated with variations in cytokine levels and are linked to fibrosis in a number of tissues. No previous work has addressed any fungal infection and TGF- $\beta 1$ polymorphism.

We found a just significant effect of the high-producing IFN- $\gamma$ T/T (+874) genotype, although not with the T allele and all forms of aspergillosis. This cytokine is known to potentiate the antifungal activity of human phagocytic cells. In an experimental mice model with invasive aspergillosis, the development of protective acquired immunity was associated with the presence of CD4+ cells producing IFN- $\gamma$ and macrophages producing IL-12, whereas impaired neutrophil antifungal activity, observed in susceptible mice, was concomitant with a predominanct production of IL-4 by CD4+ splenocytes (Cenci et al., 1997). The protective role of this TH-1 cytokine has also been documented in clinical studies (Hebart et al., 2002). This association needs further confirmation and could be artefactual.

Genetic susceptibility factors have been suggested in the case of ABPA by the occasional familial occurrence of the disease. However, in the case of CCPA, this is the first study highlighting the importance of a panel of cytokine polymorphisms in the pathogenesis of the disease and the profound role that genetic factors can play in CCPA.

A caveat of the present study, although cases and controls were adequately matched, is the low number of CCPA patients, due to the rarity of the disease, which lacks the statistical power to detect small or moderate gene effects. Moreover, we did not examine the impact of cytokine genetic polymorphisms in each clinical phenotype of CCPA patients (Denning et al., 2003). Future multicenter studies including a larger cohort of CCPA patients are required and the genetic investigation of each group separately, according to the recent classification, in order to explain on genetic grounds the clinical, radiological, histological and outcome differences among patients with CCPA. However, the commonality of some genetic defects between two manifestations of disease caused by the same organism, and the contrast between other cytokine genetic profiles (notably IL-10 and TGF- $\beta 1$ ) and different diseases is striking, and of general significance in understanding the pulmonary responses to ubiquitous airborne microorganisms.

\section{References}

Brouard, J., Knauer, N., Boelle, P.Y., Corvol, H., Henrion-Caude, A., Flamant, C. et al. (2005) Influence of interleukin-10 on Aspergillus fumigatus infection in patients with cystic fibrosis. Journal of Infectious Diseases, 191, 1988.

Cenci, E., Menacci, A., Del Sero, G. et al. (1999) Interleukin-4 causes susceptibility to invasive aspergillosis through suppression of protective type 1 responses. Journal of Infectious Diseases, 180, 1957.

Cenci, E., Mencacci, A., Bacci, A., Bistoni, F., Kurup, V.P. \& Romani, L. (2000) T cell vaccination in mice with invasive pulmonary aspergillosis. Journal of Immunology, 165, 381.

Cenci, E., Mencacci, A., Fe d'Ostiani, C. et al. (1998) Cytokine- and T helper-dependent lung mucosal immunity in mice with invasive pulmonary aspergillosis. Journal of Infectious Diseases, 178, 1750.

Cenci, E., Perito, S., Enssle, K.H., Mosci, P., Latge, J.P., Romani, L. $\&$ Bistoni, F. (1997) Th1 and Th2 cytokines in mice with invasive aspergillosis. Infection and Immunity, 65, 564.

Centeno-Lima, S., Silveira, H., Casimiro, C., Aguiar, P. \& do Rosario VE. (2002) Kinetics of cytokine expression in mice with invasive aspergillosis in lethal infection and protection. FEMS Immunology and Medical Microbiology, 32, 167.

Charpentier, J. \& Mira, J.P. (2001) Role of host response during severe bacterial infection. Archives of Pediatrics, 8 (Suppl. 4), $689 \mathrm{~s}$

Clemons, K.V., Grunig, G., Sobel, R.A., Mirels, L.F., Rennick, D. \& Stevens, D.A. (2000) Role of IL-10 in invasive aspergillosis: increased resistance of IL-10 gene knockout mice to lethal systemic aspergillosis. Clinical and Experimental Immunology, 122, 186.

Crosdale, D., Poulton, K., Ollier, W., Thomson, W. \& Denning, D.W. (2001) Mannose binding lectin gene polymorphisms as a susceptibility factor for chronic necrotising pulmonary aspergillosis. Journal of Infectious Diseases, 184, 653.

De Repentigny, L., Petitbois, S., Boushira, M. et al. (1993) Acquired immunity in experimental murine aspergillosis is mediated by macrophages. Infection and Immunity, 61, 3791.

De Rosa, F.G., Shaz, D., Campagna, A.C., Dellaripa, P.E., Khettry, U. \& Craven, D.E. (2003) Invasive pulmonary aspergillosis soon after therapy with infliximab, a tumor 
necrosis factor-alpha-neutralizing antibody: a possible healthcareassociated case? Infection Control and Hospital Epidemiology, 24, 477.

Denning, D.W., O’Driscoll, B.R., Hogaboam, C.M., Bowyer, P. \& Niven, R.M. (2006) The link between fungi and asthma - a summary of the evidence. European Respiratory Journal, 27, 615

Denning, D.W., Riniotis, K., Dobrashian, R. \& Sambatakou, H. (2003) Chronic cavitary and fibrosing pulmonary and pleural aspergillosis: case series, proposed nomenclature and review. Clinical Infectious Disease, 37 (Suppl. 3), S265.

Duong, M., Ouellet, N., Simard, M. et al. (1998) Kinetic study of host defence and inflammatory response to Aspergillus fumigatus in steroid-induced immunosuppressed mice. Journal of Infectious Diseases, 178, 1472.

Grunig, G., Corry, D.B., Leach, M.W., Seymour, B.W.P., Kurup, V.P. \& Rennick, D.M. (1997) Interleukin-10 is a natural suppressor of cytokine production and inflammation in a murine model of allergic bronchopulmonary aspergillosis. Journal of Experimental Medicine, 185, 1089.

Hebart, H., Bollinger, C., Fisch, P., Sarfati, J., Meisner, C., Baur, M., Loeffler, J., Monod, M., Latge, J.P. \& Einsele, H. (2002) Analysis of T-cell responses to Aspergillus fumigatus antigens in healthy individuals and patients with hematologic malignancies. Blood, $100,4521$.

Jack, L.D., Gary, A., Jarvis, Clare, L. et al. (2001) Mannose-binding lectin accelerates complement activation and increases serum killing of Neisseria meningitidis serogroup C. Journal of Infectious Diseases, 184, 836.

Kurup, V.P. \& Grunig, G. (2002) Animal models of allergic bronchopulmonary aspergillosis. Mycopathologia, 153, 165.

Kwiatkowski, D. (2000) Genetic dissection of the molecular pathogenesis of severe infection. Intensive Care Medicine, 26 (Suppl. 1), 89.

Levitz, S., Selsted, M.E., Ganz, T. et al. (1986) In vitro killing of spores and hyphae of Aspergillus fumigatus and Rhizopus oryzae by rabbit neutrophil cationic peptides and bronchoalveolar macrophages. Journal of Infectious Diseases, 154, 483.

Lofgren, J., Ramet, M., Renko, M. et al. (2002) Association between surfactant protein a gene locus and severe respiratory syncytial virus infection in infants. Journal of Infectious Diseases, 185, 283.

Madan, T., Kaur, S., Saxena, S., Singh, M., Kishore, U., Thiel, S., Reid, K.B. \& Sarma, P.U. (2005) Role of collectins in innate immunity against aspergillosis. Medical Mycology, 43 (Suppl. 1), S155.

McNicholl, J.M., Downer, M.V., Udhayakumar, V. et al. (2000) Host-pathogen interactions in re-emerging infectious diseases: a genomic perspective of tuberculosis, malaria, human immunodeficiency virus infection, hepatitis B, and cholera. Annual Review of Health, 21, 15.

Mehrad, B., Strieter, R.M. \& Standiford, T.J. (1999) Role of TNFalpha in pulmonary host defence in murine invasive aspergillosis. Journal of Immunology, 162, 1633.
Mencacci, A., Cenci, E., Bacci, A. et al. (2000) Cytokines in candidiasis and aspergillosis. Current Pharmaceutical Biotechnology, 1, 235.

Nagai, H., Guo, H., Choi, H. \& Kurup, V. (1995) Interferon- $\gamma$ and tumor necrosis factor- $\alpha$ protect mice from invasive aspergillosis. Journal of Infectious Diseases, 172, 1554.

Nierman, W., Pain, A., Anderson, M.J., Wortman, J., Arroya, J., Berriman, B. et al. (2005) Genomic sequence of the pathogenic and allergenic Aspergillus fumigatus. Nature, 438, 1151.

Perrey, C., Pravica, V., Sinnott, P.J. \& Hutchinson, I.V. (1998) Genotyping for polymorphisms in interferon- $\gamma$, interleukin-10, transforming growth factor-b1 and tumour necrosis factor- $\alpha$ genes: a technical report. Transplant Immunology, 6, 193.

Pravica, V., Perrey, C., Stevens, A., Lee, J.H. \& Hutchinson, I.V. (2000) Single nucleotide polymorphism in the first intron of the human IFN-gamma gene: absolute correlation with a polymorphic CA microsatellite marker of high IFN-gamma production. Human Immunology, 61, 863.

Rhodes, J.C. (1993) Aspergillosis. In: Fungal Infections and Immune Responses (ed. by J.W. Murphy, H. Friedman \& M. Bendinelli). New York, Plenum Press, 359.

Roilides, E., Dimitriadou -Georgiadou, A., Sein, T., Kadiltsoglou, I. \& Walsh, T. (1998) Tumor necrosis factor alpha enhances antifungal activities of polymorphonuclear and mononuclear phagocytes against Aspergillus fumigatus. Infection and Immunity, 66, 5999.

Roilides, E., Blake, C., Holmes, A., Pizzo, P.A. et al. (1996) Granulocytemacrophage colony-stimulating factor and interferon-gamma prevent dexamethasone-induced immunosuppression of antifungal monocyte activity against Aspergillus fumigatus hyphae. Journal of Medical Mycology, 34, 63.

Roilides, E., Sein, T., Roden, M., Schaufele, R.I. \& Walsh, T.J. (2001) Elevated serum concentrations of interleukin-10 in nonneutropenic patients with invasive aspergillosis. Journal of Infectious Diseases, 183, 518.

Schaffner, A., Douglas, H. \& Braude, A. (1982) Selective protection against conidia by mononuclear and against mycelia by polymorphonuclear phagocytes in resistance to Aspergillus: observations on these two lines of defense in vivo and in vitro with human and mouse phagocytes. Journal of Clinical Investigations, 69, 617.

Waldorf, A.R., Levitz, S. \& Diamond, R.D. (1984) In vivo bromchoalveolar macrophage defense against Rhizopus oryzae and Aspergillus fumigatus. Journal of Infectious Diseases, 150, 752.

Winn, R.M., Gil-Lamaignere, C., Roilides, E., Simitsopoulou, M., Lyman, C.A., Maloukou, A. \& Walsh, T.J. (2003) Selective effects of interleukin (IL)-15 on antifungal activity and IL-8 release by polymorphonuclear leukocytes in response to hyphae of Aspergillus species. Journal of Infectious Diseases, $188,585$. 